\title{
Persist or Produce: A Community Trade-Off Tuned by Species Evenness
}

\author{
Rudolf P. Rohr, ${ }^{1, *, \dagger}$ Serguei Saavedra, ${ }^{2, \dagger}$, Guadalupe Peralta, ${ }^{3, \$}$ Carol M. Frost, ${ }^{3, \|}$ \\ Louis-Félix Bersier, ${ }^{1}$ Jordi Bascompte, ${ }^{4, \#}$ and Jason M. Tylianakis ${ }^{3,5}$
}

1. Department of Biology_Ecology and Evolution, University of Fribourg, Chemin du Musée 10, CH-1700 Fribourg, Switzerland; 2. Department of Environmental Systems Science, Swiss Federal Institute of Technology Zurich, Universitätstrasse 16, CH-8092 Zurich, Switzerland; and Department of Evolutionary Biology and Environmental Studies, University of Zurich, Winterthurerstrasse 190, CH-8057 Zurich, Switzerland; 3. Centre for Integrative Ecology, School of Biological Sciences, University of Canterbury, Private Bag 4800, Christchurch 8140, New Zealand; 4. Integrative Ecology Group, Estación Biológica de Doñana (EBD-CSIC), Calle Américo Vespucio s/n, E-41092 Seville, Spain; 5. Department of Life Sciences, Imperial College London, Silwood Park Campus, Buckhurst Road, Ascot SL5 7PY, United Kingdom

Submitted December 7, 2015; Accepted May 19, 2016; Electronically published August 3, 2016

Online enhancements: appendixes, supplemental figures. Dryad data: http://dx.doi.org/10.5061/dryad.sp45r.

\begin{abstract}
Understanding the effects of biodiversity on community persistence and productivity is key to managing both natural and production systems. Because rare species face greater danger of extinction, species evenness, a measure of how similar abundances are across species in a community, is seen as a key component of biodiversity. However, previous studies have failed to find a consistent association of species evenness with species survival and biomass production. Here we provide a theoretical framework for the relationship among these three elements. We demonstrate that the lack of consistent outcomes is not an idiosyncratic artifact of different studies but can be unified under one common framework. Applying a niche theory approach, we confirm that under demographic stochasticity evenness is a general indicator of the risk of future species extinctions in a community, in accordance with the majority of empirical studies. In contrast, evenness cannot be used as a direct indicator of the level of biomass production in a community. When a single species dominates, as expressed by the constraints imposed by the population dynamics, biomass production depends on the niche position of the dominating species and can increase or decrease with evenness. We
\end{abstract}

\footnotetext{
* Corresponding author; e-mail: rudolf.rohr@unifr.ch.

$\dagger$ These authors contributed equally to this work.

* Present address: Department of Civil and Environmental Engineering, Massachusetts Institute of Technology, Cambridge, Massachusetts 02139.

${ }^{\S}$ Present address: Instituto Argentino de Investigaciones de las Zonas Áridas, Consejo Nacional de Investigaciones Científicas y Técnicas (CONICET), CC 507, 5500 Mendoza, Argentina.

"I Present address: Department of Forest Ecology and Management, Swedish University of Agricultural Sciences, Skogsmarksgränd, 90183 Umeå, Sweden.

\# Present address: Department of Evolutionary Biology and Environmental Studies, University of Zurich, Winterthurerstrasse 190, CH-8057 Zurich, Switzerland.

ORCIDs: Rohr, http://orcid.org/0000-0002-6440-2696; Frost, http://orcid.org /0000-0003-3805-5528; Bersier, http://orcid.org/0000-0001-9552-8032; Tylianakis, http://orcid.org/0000-0001-7402-5620.

Am. Nat. 2016. Vol. 188, pp. 411-422. (C) 2016 by The University of Chicago. 0003-0147/2016/18804-56695\$15.00. All rights reserved.

DOI: $10.1086 / 688046$
}

demonstrate that high species evenness and an intermediate level of biomass production is the configuration that maximizes the average species survival probability in response to demographic stochasticity.

Keywords: biodiversity, competition systems, demographic stochasticity, ecosystem functioning, niche theory, species coexistence.

\section{Introduction}

Biodiversity is a central concern in conservation, in part due to its relationship with ecosystem processes, such as biomass production (Margalef 1963; Odum 1969; Tilman et al. 1996; Chapin et al. 2000; Loreau 2010; Vellend et al. 2013). This relationship has even generated interest as a means to augment biomass in production systems, such as plantation forests (Erskine et al. 2006). However, biodiversity has traditionally been measured in these studies as species richness (Hooper et al. 2005), whereas the majority of species in a community are normally found to occur in low abundance, with only a few being extremely common (Preston 1948; Tokeshi 1990; Chapin et al. 2000; Sugihara et al. 2003).

Because rare species might be more vulnerable to demographic stochasticity under environmental stress, an equally relevant index of biodiversity is species evenness, that is, how similar abundances are across species (Levins 1968; Margalef 1968; Odum 1969; Chapin et al. 2000; Stirling and Wilsey 2001). Furthermore, species evenness may respond more rapidly to environmental changes than does richness (Chapin et al. 2000), so researchers have hypothesized that changes to species evenness may be a good indicator of the risk of future species extinctions in a community (Odum 1969; Chapin et al. 2000; Halloy and Barratt 2007). This hypothesis has also been supported experimentally by several studies (see table A1; tables A1, A2 are available online). 
Despite its potential utility as a measure of ecosystem state, research testing the influence of species evenness on ecosystem functioning has found more variable results than that for richness (Hillebrand et al. 2008), although the majority of these effects have been positive (see table A2). Although positive effects of species evenness on biomass production have been shown both theoretically (Nijs and Roy 2000) and empirically (Wilsey and Potvin 2000; see table A2), abiotic drivers of evenness (or of its reciprocal, dominance) may reverse this relationship (Mulder et al. 2004). For example, abundant resources can promote competitive dominance by a few species and lead to reduced species richness and higher growth rates (Laliberté et al. 2013), in accordance with theory (Huston 1979). When abiotic stress subsequently reduces this dominance, the resulting increase in evenness may be associated with lower biomass production (Wardle et al. 1997). Theoretical (Norberg et al. 2001) and experimental (Wittebolle et al. 2009) results suggest that systems with low species evenness may be less resistant to stress induced by environmental change. This suggests that there may be an intricate balance between competition (via its effect on species evenness), community persistence, and ecosystem functioning. Yet the nature of this relationship remains a major conceptual challenge (Wittebolle et al. 2009).

Given the prominent role played by species evenness in both the persistence and the productivity of communities, we build a conceptual framework based on niche theory whereby these axes can be viewed simultaneously, with the hope that this approach will shed light on apparently contradictory results. Our aim is to study the relationship among these three properties under a Lotka-Volterra framework and under the constraints imposed by the differential equations describing the population dynamic. In particular, to estimate species survival probability, we assumed stochastic noise in the demographic parameters. While our approach is focused exclusively on the relationship between community evenness and species survival probability, we also search for general patterns of context dependency by examining the conditions under which a competition hierarchy would be expected to generate a trade-off between productivity and evenness rather than a positive relationship between these two ecosystem measurements.

The article is organized as follows. First, we explain our theoretical framework based on niche theory. Second, we explain how we calculate species evenness, community biomass, the average survival probability of species under stochastic noise in demographic parameters, and the link among the three of them. Third, we explain how to disentangle the role played by species evenness and biomass production in shaping species survival probability under demographic stochasticity. Finally, we explore the outcomes of our framework and discuss their implications.

\section{Methods \\ Theoretical Framework}

Our theoretical framework of population dynamics is based on the generalized Lotka-Volterra competition model derived from niche theory (MacArthur and Levins 1967; Levins 1968; Svirezhev and Logofet 1983; Logofet 1993; Loreau 2010; Saavedra et al. 2014). Mathematically, the dynamical model is given by

$$
\frac{\mathrm{d} N_{i}}{\mathrm{~d} t}=\frac{r_{i}}{K_{i}} N_{i}\left(K_{i}-\sum_{j=1}^{s} \alpha_{i j} N_{j}\right),
$$

where variable $N_{i} \geq 0$ denotes the biomass of species $i$. The parameters are as follows: $r_{i}>0$ represents the growth rate of species $i, K_{i}>0$ indicates the carrying capacity of species $i$ (i.e., the biomass at equilibrium in monoculture), and $\alpha_{i j} \geq 0$ indicates the niche overlap between species $i$ and $j$, which gives the competitive effect of species $j$ on species $i$.

Assuming a $D$-dimensional niche space and that each species' niche is represented by a multivariate Gaussian-like function, the niche overlap between two species $\left(\alpha_{i j}\right)$ can be expressed as a function of their distance in the niche space (MacArthur and Levins 1967; Levins 1968; Svirezhev and Logofet 1983; Logofet 1993):

$$
\alpha_{i j}=\exp \left(-d_{i j}^{2} / 4 \sigma^{2}\right),
$$

where $\sigma$ is the niche width (assumed to be the same for all species and in all of the $D$-dimensions of the niche space) and $d_{i j}$ is the distance between species $i$ and species $j$. The pairwise niche distances are computed by $d_{i j}=\left\|\boldsymbol{\mu}_{i}-\boldsymbol{\mu}_{j}\right\|$, where the vector $\boldsymbol{\mu}_{i}$ gives the position of species $i$ in the niche space. By definition, we have $\alpha_{i i}=1$, so that in the absence of pairwise niche overlap (or equivalently when species are in monoculture) each species reaches its own carrying capacity at equilibrium (Levins 1968).

Note that without loss of generality, we can rewrite equation (1) in the form $\mathrm{d} N_{i} / \mathrm{d} t=N_{i}\left(r_{i}-\sum_{j} A_{i j} N_{j}\right)$, where $A_{i j}$ is the competition strength matrix and is linked to the niche overlap matrix by $A_{i j}=r_{i} / K_{i} \alpha_{i j}$. The matrix $A_{i j}$ is in general asymmetric (because $r_{i}$ and $K_{i}$ are different among species) and expresses the per capita effect of species $j$ on the per capita growth rate of species $i$. The elements of the niche overlap matrix $\alpha_{i j}$ are dimensionless, while the competition strength has units time ${ }^{-1}$ biomass $^{-1}$ or $\left(\right.$ time ${ }^{-1}$ abundance $\left.{ }^{-1}\right)$. This expression can be generalized, without changing qualitatively the results, to incorporate species dependence on the width and amplitude of the niche curve (app. B; apps. A-C are available online).

Importantly, a niche-based competition model has two advantages for a theoretical framework, one technical and one conceptual (Case 1990). The technical advantage is that in a Lotka-Volterra model (eq. [1]) based on a competition 
matrix ( $\boldsymbol{\alpha})$ derived from a niche space (e.g., eq. [2]), the trajectory of the dynamical system will converge to a unique globally stable equilibrium point (independent of the initial conditions). This is the consequence of the niche overlap matrix being inevitably Volterra dissipative (Volterra 1931; Svirezhev and Logofet 1983; Logofet 1993). Therefore, if one randomly generates an interaction matrix $\boldsymbol{\alpha}$ by sampling randomly the niche positions and then computing the pairwise niche overlap elements, the biomass values at equilibrium are dictated only by the carrying capacities and not by the intrinsic growth rates (Saavedra et al. 2014), and that equilibrium point is globally stable. In contrast, if one generates a competition matrix by drawing directly the niche overlap at random, then the global stability property is not granted anymore. The conceptual advantage is that by calculating the competition coefficients derived from a niche overlap framework rather than drawing them directly at random, one can provide a clear biological and mechanistic interpretation based on competition for common resources.

\section{Species Evenness}

Species evenness is a measure of how equally biomass is distributed among species in a given community. Traditionally, species evenness is calculated as the Pielou index by

$$
J=-\frac{\sum_{i} p_{i} \log p_{i}}{\log S}
$$

where $p_{i}=N_{i}^{*} / \sum_{j} N_{j}^{*}$ is the fraction of species $i$ 's biomass (from the total biomass in the community) and $S$ is the total number of species in the community. Species evenness, defined for $S>1$, takes values in $[0,1]$, where a value of 1 indicates that all species are equally abundant and a low value indicates that the community is dominated by a few or a single species.

\section{Community Biomass}

In the presence of interspecific competition, the total biomass of a community at the steady state of a Lotka-Volterra model (eq. [1]) is less than the sum of all the carrying capacities of the constituent species. The ratio between the total biomass at equilibrium and the sum of all carrying capacities can be used as a proxy for the relative biomass production in a community. This ratio is computed as

$$
P=\frac{\sum_{i} N_{i}^{*}}{\sum_{i} K_{i}} .
$$

The ratio $P$ is dimensionless and represents the fraction of potential biomass production achieved in the presence of interspecific competition. Our intent in using this ratio, rather than simply summed biomass, is to account for inherent productivity differences across communities and thereby allow these results to be comparable across different distributions of species biomasses (Cardinale et al. 2006). For example, some species may naturally occur at low biomass because they have specialized niches, tend to occur in lowresource environments, or never achieve a large size. Increasing evenness may also appear to lead to an augmentation in biomass, simply because it involves an increase in the carrying capacity of species that have a low biomass. Our use of relative biomass therefore measures the competitionlimited biomass of such species relative to their biomass in the absence of competition and is akin to the measure used to assess overyielding (the change in biomass beyond that obtained by each species in isolation) in biodiversity-productivity studies (Loreau 1998; Cardinale et al. 2006; Hector and Bagchi 2007).

\section{Average Survival Probability of Species under Demographic Stochasticity}

To obtain an estimation of the survival probability of any species in a community, we calculated the average fraction of surviving species under demographic stochasticity. Specifically, for a given community represented by a niche overlap matrix $(\boldsymbol{\alpha})$ and a given biomass distribution $\boldsymbol{N}^{*}$, this average survival probability is calculated in the following way.

First, given $\boldsymbol{\alpha}$ and $\boldsymbol{N}^{*}$, we compute the corresponding vector of carrying capacities by $K=\alpha N^{*}$. This vector of carrying capacities is the one that makes the Lotka-Volterra model (eq. [1]) converge to the biomass distribution $N^{*}$ at equilibrium. Our theoretical framework assumes that the biomass distribution, the niche overlap matrix, and the carrying capacities are constrained by the equation for the community dynamics.

Second, we mimic demographic stochasticity by introducing random and proportional variations to the calculated vector of carrying capacities $\boldsymbol{K}$. This is done by multiplying each of the vector elements by a lognormal random number of mean 0 and standard deviation $0.3,0.1$, and 0.01 for a high, medium, and low level of environmental stochasticity, respectively. Note that this simulated environmental stochasticity on the carrying capacities is equivalent to simulated stochasticity on the intrinsic growth rate, as the carrying capacity in a competitive framework is given by the ratio between the intrinsic growth rate and the fixed intraspecific competition.

Finally, using these perturbed vectors of carrying capacities, we computed the fraction of surviving species at the steady state of the Lotka-Volterra model (eq. [1]). To obtain an estimation of the average survival probability of species, we repeated steps two and three 200 times and computed 
the average fraction of surviving species under demographic stochasticity.

\section{Linking Evenness, Biomass Production, and Species Survival Probability}

To study the theoretical link among species evenness, biomass production, and survival probability of species in any given community represented by a niche overlap matrix $\boldsymbol{\alpha}$, we took an approach of exploring as exhaustively as possible the biomass production-evenness space and estimating the survival probabilities. This approach followed three steps.

First, we randomly generated the niche position of each species in a two-dimensional niche space and computed the niche overlap matrix $\boldsymbol{\alpha}$ (eq. [2]). The two coordinates of each species were sampled uniformly between 0 and 1 . The niche width was chosen such that the average interspecific niche overlap was within the range $[0.05,0.3]$. The results are qualitatively robust to changes in the dimension of the niche space (results not shown).

Second, because our aim is to study the association imposed by the Lotka-Volterra model of species survival probability with biomass production and species evenness for a fixed number of species $S$, we generated a full gradient of species evenness from almost 0 to 1 . To achieve such a gradient we could have randomly sampled vectors of carrying capacities and then computed the biomass of the species at the equilibrium point of the Lotka-Volterra model. However, for many of these simulated vectors of carrying capacities, the equilibrium point would have few or many species extinct. Then these vectors of carrying capacities leading to species extinction would need to be disregarded. This, of course, would represent a considerable amount of computational time. Therefore, to achieve our gradient of evenness efficiently from a computational perspective, we decided to first generate the distributions of biomass and then compute their corresponding vector of carrying capacities (expressed by the equation $K=\alpha N^{*}$ ). These biomass distributions were sampled from a lognormal distribution of location parameter 0 and scale parameter drawn uniformly between 0 and 5 . Note that our biomass sampling procedure explores intensively the full domain of potential biomass distributions and, consequently, the full domain in the parameter space of carrying capacity compatible with coexistence. Therefore, our findings are general because they do not depend on a specific parameterization of demographic parameters (Rohr et al. 2014). We sampled 20,000 species biomass distributions.

Finally, for each niche overlap matrix $(\boldsymbol{\alpha})$ and each generated distribution of species biomass $\left(\boldsymbol{N}^{*}\right)$, we computed the corresponding level of species evenness (eq. [3]), relative biomass production (eq. [4]), and average species survival probability under demographic stochasticity.

\section{Feasibility Analysis}

To understand the role played by species evenness and biomass production in shaping the average species survival probability, we studied the feasibility domain of each simulated community (Svirezhev and Logofet 1983; Logofet 1993; Rohr et al. 2014; Saavedra et al. 2014, 2016a, 2016b). In this context, the feasibility domain corresponds to the domain in the parameter space of carrying capacities compatible with the survival of all species, that is, given $\boldsymbol{\alpha}$ it is the set of carrying capacities such that their equilibrium points under the Lotka-Volterra model (eq. [1]) yield solutions where all species have a strictly positive biomass, $N_{i}^{*}>$ 0 . Outside this domain, there is no set of carrying capacities leading to the survival of all species. Mathematically, the feasibility domain is defined by

$$
\begin{aligned}
D_{F}(\boldsymbol{\alpha})=\{ & \boldsymbol{K} \in \mathbf{R}_{>0}^{S} \mid \text { there exist } \boldsymbol{N}^{*} \text { with } N_{i}^{*}>0 \\
& \text { such that } \left.\boldsymbol{K}=\alpha \boldsymbol{N}^{*}\right\} .
\end{aligned}
$$

If one chooses a vector of carrying capacities $(\boldsymbol{K})$ inside that domain, then by definition the Lotka-Volterra model (eq. [1]) converges to a positive equilibrium point given by $N^{*}=\alpha^{-1} K$

The feasibility domain of a niche overlap matrix $\boldsymbol{\alpha}$ is geometrically represented by an algebraic cone in the space of carrying capacities (Svirezhev and Logofet 1983; Logofet 1993). A vector of carrying capacities close to its border is, by definition, more at risk of species extinction under demographic stochasticity. That is, the chances that a stochastic perturbation pushes the vector of carrying capacities outside the domain of feasibility (which implies that at least one species is becoming extinct) is larger for vectors closer to the border. Therefore, to increase the average survival probability, one possibility is to locate the vector at the center of the feasibility domain. Note that the geometric centroid of the cone describing the feasibility domain is one possible center. This geometric centroid, defined by the so-called structural vector $\boldsymbol{K}^{\boldsymbol{S}}(\boldsymbol{\alpha})$ (Rohr et al. 2014; Saavedra et al. 2014), can be computed on the basis of the elements of the niche overlap matrix by the following formula:

$$
K_{i}^{S}(\boldsymbol{\alpha})=\sum_{j=1}^{S} \frac{\alpha_{i j}}{\sum_{k=1}^{S} \alpha_{k j}} .
$$

For any vector of carrying capacities $K$, we calculate its deviation from the centroid $\boldsymbol{K}^{S}(\boldsymbol{\alpha})$ by the angle between the two vectors (Rohr et al. 2014; Saavedra et al. 2014). This deviation is computed on the basis of the scalar product:

$$
\theta=\arccos \left(\frac{\sum_{i=1}^{S} K_{i} K_{i}^{S}}{\sqrt{\sum_{i=1}^{S} K_{i}^{2}} \sqrt{\sum_{i=1}^{S}\left(K_{i}^{S}\right)^{2}}}\right) .
$$


We stress that the notions of feasibility domain, structural vector, and deviation provide a mechanistic understanding of the dynamics of the community as a whole and are contained in the Lotka-Volterra model (eq. [1]). The average survival probability cannot be deduced directly but requires simulations and the addition of demographic stochasticity for its estimation.

\section{Results}

To explore the relationship among species survival probability, species evenness, and biomass production, we constructed randomly assembled communities of 10, 15, 20, 25 , and 30 species. For each level of species richness, we generated communities with an average interspecific niche overlap within the range of $[0.05,0.3]$. For other overlap values, the results are qualitatively equivalent. For each niche overlap matrix, we sampled communities spanning the whole range of species evenness. Finally, for each generated community we explored three levels of stochastic noise (standard deviation of $0.01,0.1$, and 0.3 ) on the demographic parameters to estimate survival probabilities.

\section{Species Evenness and Survival Probability}

We found a positive and strong relationship between the level of species evenness and the average survival probability of each species (fig. 1A). Note that the actual values of survival probability are completely dependent on the parameters used for the community and perturbations. Importantly, the level of random perturbations does not change the relationship between species evenness and survival probability, and this pattern is highly reproducible in simulated communities of different sizes and is characterized by different average niche overlap (figs. S1-S15; figs. S1-S44 are available online). It is worth mentioning that an increase in the average niche overlap always results in an overall decrease in the average survival probability, keeping fixed the number of species and the level of demographic stochasticity (figs. S16-S20). This negative relationship between niche overlap and survival probability is perfectly in line with previous studies showing that an increase in competition results in a decrease in the feasibility domain (Vandermeer 1970; Bastolla et al. 2005; Saavedra et al. 2014). We also explored community evenness using the Simpson index (figs. S36S44), and the results are qualitatively equivalent. In general, these findings reveal that community evenness is directly and positively linked to the likelihood of species survival, providing a theoretical justification for the use of evenness as a proxy for the probability of future species extinctions under demographic stochasticity (Odum 1969; Chapin et al. 2000; Halloy and Barratt 2007).

\section{Species Evenness and Biomass Production}

In contrast to the direct relationship between species evenness and survival probability, we found a multidirectional relationship between species evenness and relative biomass (fig. $1 B$ ). Figure $1 B$ shows that at the maximum level of species evenness, relative biomass is at an intermediate level compared with its total possible range. When species evenness decreases from this maximum, relative biomass can either increase or decrease. Specifically, if the species that has the lowest average niche overlap with the other species (computed as $\left.\bar{\alpha}_{i}=\left(\sum_{j \neq i} \alpha_{i j}\right) /(S-1)\right)$ dominates the community, a decrease in species evenness implies an increase in relative biomass. Alternatively, if the dominating species has a high average niche overlap, the relative biomass decreases with declining evenness (fig. $1 B$ ). It can be mathematically proven that lower average niche overlap of the dominating species leads to large relative biomass and vice versa (see app. C for the mathematical proof). This implies that species evenness cannot be used as a direct predictor of the relative biomass of a community. In a community dominated by a single species, the relative biomass depends on the niche overlap of the dominating species and can thus increase or decrease with evenness. These results are robust to the change in species richness and average niche overlap (figs. S1-S15).

The computer code for reproducing the simulations can be downloaded from the Dryad Digital Repository: http:// dx.doi.org/10.5061/dryad.sp45r (Rohr et al. 2016).

\section{Theoretical Explanation for the Link among Evenness, Biomass Production, and Survival Probability}

In this section, we first explain why the positive relationship between evenness and survival probability should be theoretically expected. Then we show how the deviation from the centroid of the feasibility domain of a community can be used to disentangle the relationship between species evenness and biomass production.

We start by providing an illustrated example of the feasibility domain and its implications for the average survival probability of species. Figure $2 A$ represents the algebraic cone of the feasibility domain. Each axis corresponds to the carrying capacity values of a species (parameter space), which define the solution of the system (state space; Svirezhev and Logofet 1983; Logofet 1993; Saavedra et al. 2016a, 2016b). The cone is generated by the three blue vectors, which provide the limits of the feasibility domain. The dashed vector represents the centroid of the feasibility domain (the structural vector). Figure $2 B$ shows a two-dimensional slice of the cone in figure $2 A$. The outer triangle (gray) corresponds to the total domain of carrying capacities and is split into seven domains. The inner triangle (red) corresponds to the feasibility 


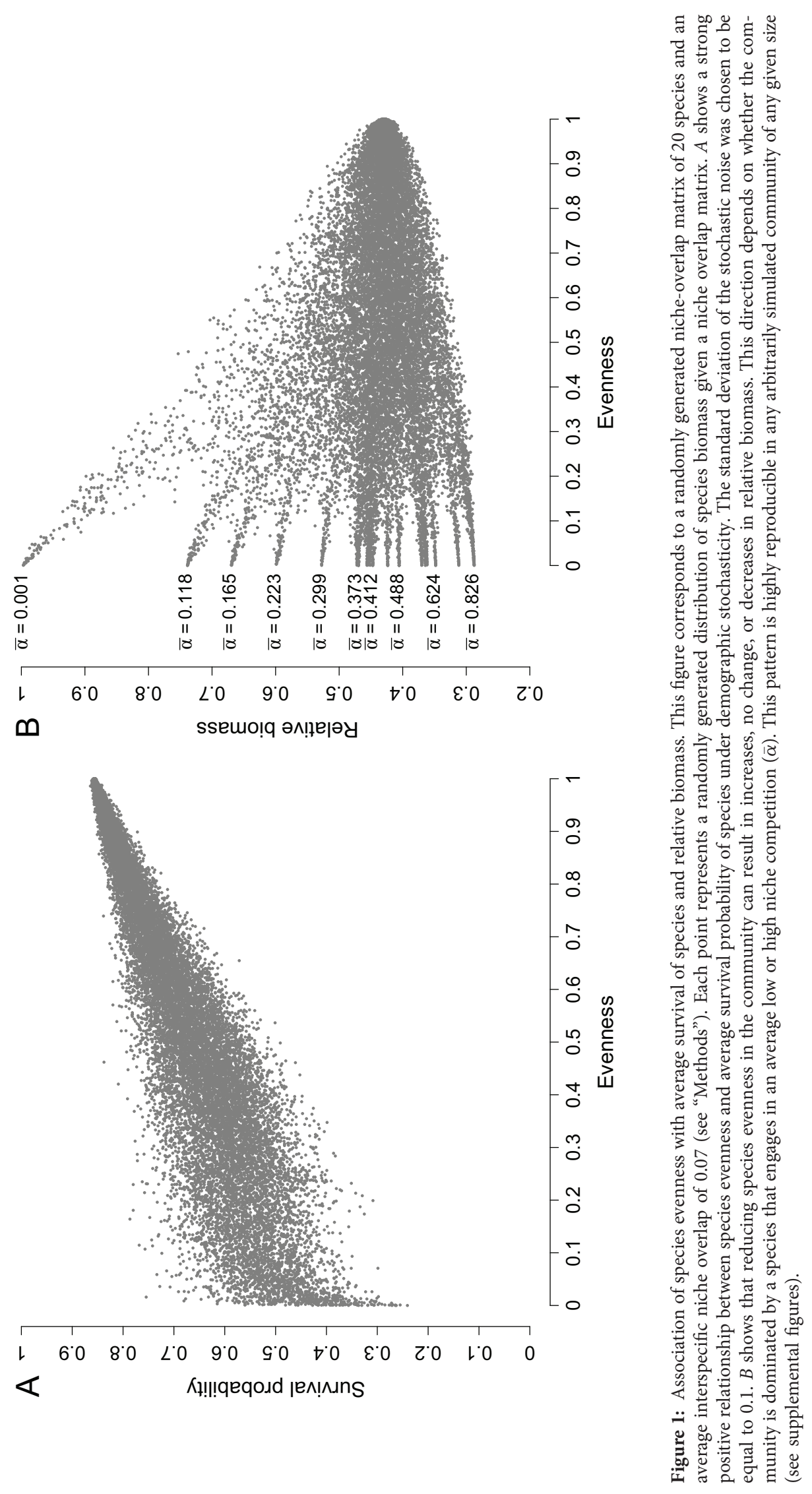



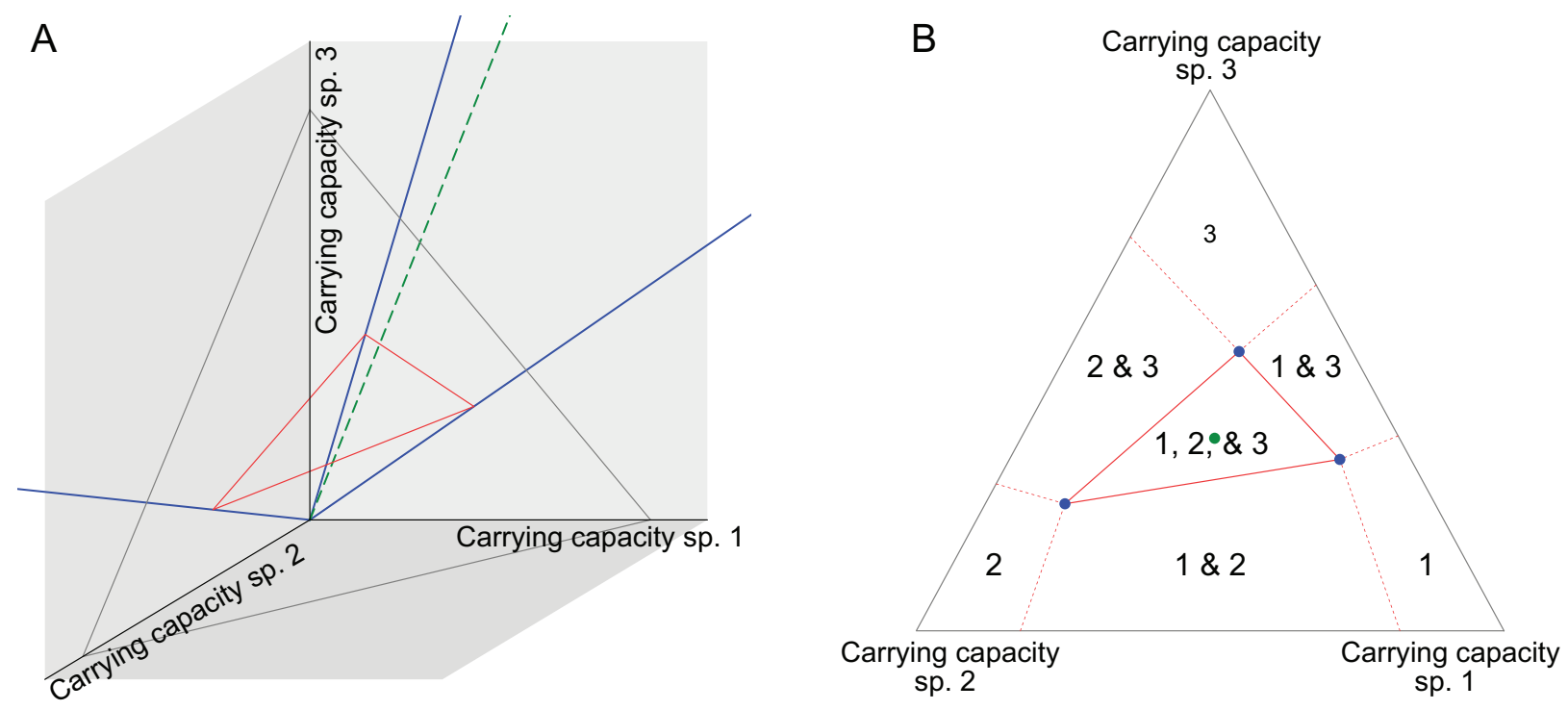

Figure 2: Graphical representation of the feasibility domain. A corresponds to the projection of the community shown in figure 1 on a subset of three randomly chosen species. The three black axes represent the full domain of carrying capacities. The angle formed by the three blue lines corresponds to the algebraic cone of the feasibility domain, that is, the subset of carrying capacities leading the positive biomass for the three species at the stable steady states of the Lotka-Volterra model. The dashed line in the middle (green) corresponds to the centroid of the feasibility domain (structural vector). To simplify the representation of the feasibility domain, we can take a slice of the full domain. This slice is represented by the outer gray triangle. The red inner triangle is the corresponding slice of the feasibility cone. $B$ is a two-dimensional representation of the slice of $A$. The outer gray triangle is split into seven domains. The inner red triangle represents the feasibility domain (the three species have positive biomass at equilibrium), while in the other six domains at least one species becomes extinct. The identity of the surviving species is given by the numbers inside the domain. Note that the slice is the projection of the full space on the unit simplex, that is, where the sum of the carrying capacity is equal to 1 . Therefore, the slice is a complete representation of carrying capacities space up to a scaling factor.

domain, where all three species survive (a larger feasibility domain indicates a greater range of parameters leading to a positive solution). In the other six domains, at least one species becomes extinct. The identity of the surviving species is given by the number(s) inside the corresponding domain. Each blue dot at the border of the feasibility cone represents the limit at which one of the three species is fully dominating the system; the green symbol in the middle corresponds to the centroid of the feasibility domain.

Importantly, these figures allow us to provide a theoretical explanation for the positive relationship between evenness and survival probability, as follows. As explained in the feasibility analysis section, a vector of carrying capacities located closer to the border of the feasibility domain is more at risk, under demographic stochasticity, of species extinctions. Therefore, it should be theoretically expected that the closer a vector of carrying capacities is to the border of the feasibility domain, the lower will be the average survival probability of the species. Figure $3 A$ represents the same feasibility domain as in figure $2 B$, where the heat map inside the triangle now shows the average survival probability of species. This figure confirms our theoretical expectation.
Similarly, the closer the vector of carrying capacities is located to the border of the feasibility domain, the lower the level of species evenness (fig. $3 B$ ). This is true because at the borders, by definition, one or more species are on the brink of extinction and have very low biomass compared with the others. For instance, the extreme case is when a vector is located at one of the corners of the feasibility domain (blue dots on fig $2 B$ ). In that case, one species completely dominates the system, and species evenness is close to 0 . The heat map inside the feasibility domain of figure $3 B$ shows that as soon as we start moving away from the centroid of the feasibility domain, the level of species evenness starts to decrease. This confirms again our theoretical expectation.

In contrast, figure $3 C$ confirms that there is a very different pattern for community biomass. The figure shows the same representation as figure $3 A$ and $3 B$, but this time the heat map inside the triangle corresponds to the relative biomass. This shows that the direction taken from the centroid of the feasibility domain plays an important role in determining the level of community biomass. The community biomass will be maximized (minimized) if the deviation from the centroid moves toward the species with the lowest 


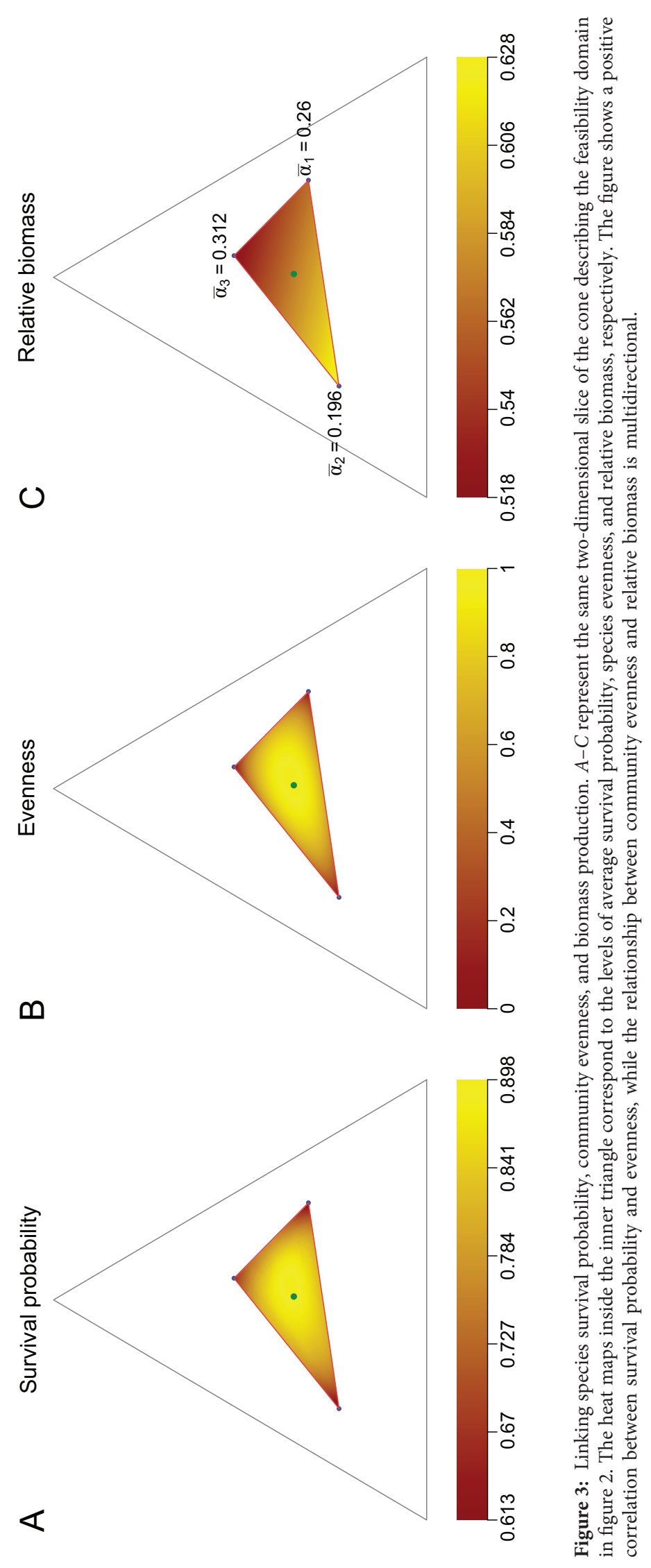


(largest) average niche overlap. See appendix C for a mathematical demonstration.

Extending the three-species illustration to the entire community, figure 4 shows the relationship among deviation from the centroid of the feasibility domain, species evenness, and relative biomass production. First, as expected, the figure shows a clear negative relationship between species evenness and the deviation from the centroid of the feasibility domain. Second, the figure confirms that high relative biomass production is inevitably associated with a low level of species evenness and high deviation from the centroid of the feasibility domain. This pattern is highly reproducible in any arbitrarily simulated community of any given size and level of average interspecific niche overlap (figs. S21-S35).

These findings confirm that the centroid of the feasibility domain of a niche-competition community (the configuration that allows the largest demographic stress without species extinctions) can be achieved only with high species evenness and an intermediate level of relative biomass. Moreover, these theoretical findings suggest that species evenness can be the result of a fundamental trade-off between species survival probability (or deviation from the centroid of the feasibility domain) and community biomass. In our setting, this trade-off is imposed by the population dynamic. As a consequence, it is not possible to reach a high relative biomass while assuring a low extinction probability in the community.

\section{Discussion}

Previous studies have failed to find a consistent relationship between species evenness and biomass production (see table A2 for a detailed review of the topic). Our results demonstrate that these mixed outcomes are not idiosyncratic artifacts of different studies but rather represent equally plausible community trajectories under demographic stochasticity. These trajectories are associated with declining

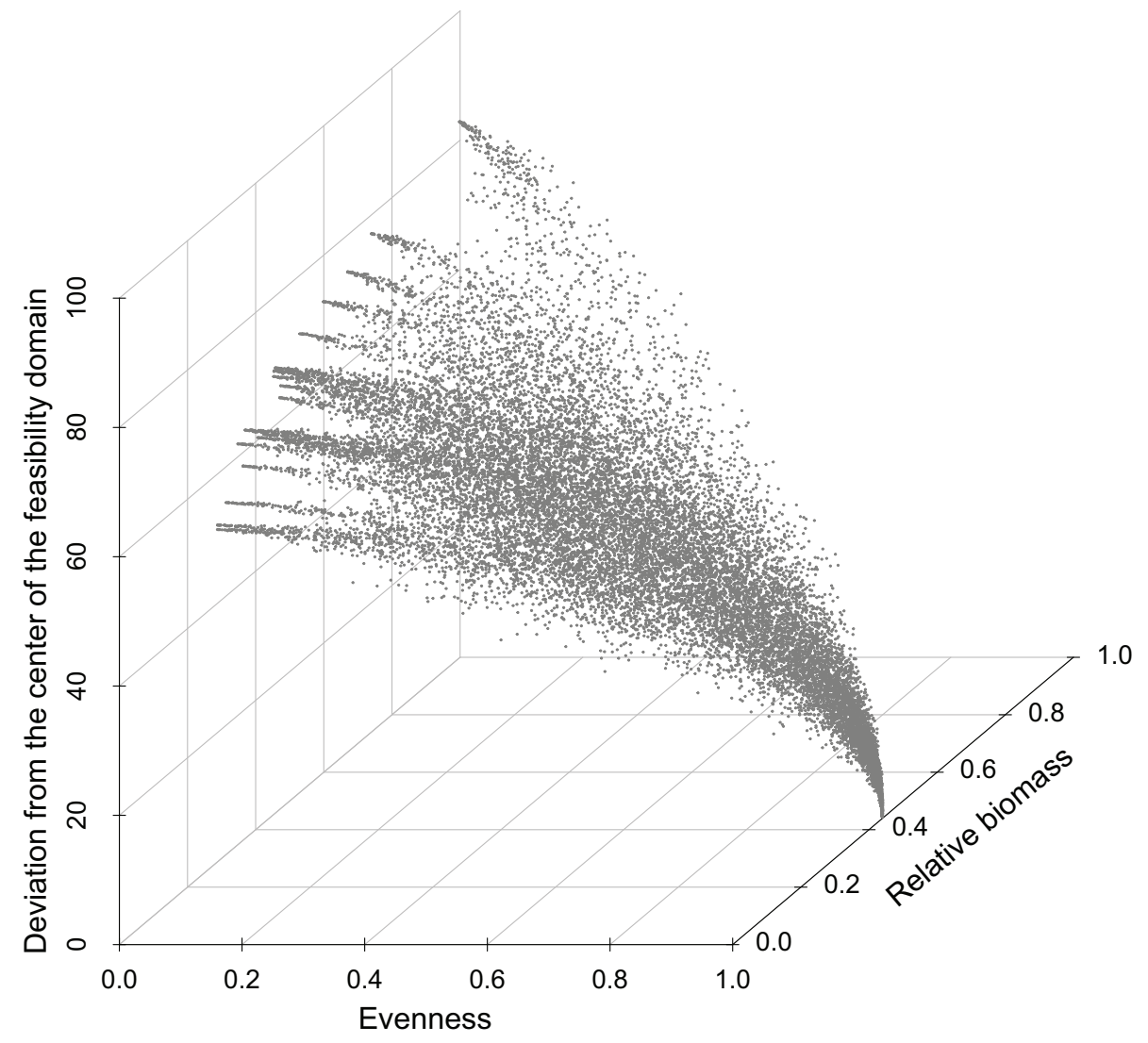

Figure 4: Disentangling the effects of species evenness and biomass production on species survival. The figure shows the relationship among deviation from the centroid of the feasibility domain, species evenness, and relative biomass for the full community shown in figure 1 . The larger the deviation is, the lower the average species survival probability under demographic stochasticity. This illustrates that both species evenness and relative biomass production are the result of a given level of deviation of the community from the centroid of its feasibility domain. Each point represents a randomly generated distribution of species biomass. This pattern is highly reproducible in any arbitrarily simulated community of any given size and level of average niche overlap (see supplemental figures). 
species evenness. They have the largest positive slope in communities that achieve maximal relative biomass production as a result of the low niche-competitive effect of the dominating species on the other species in the community. Conversely, they have a negative slope if the dominant species is in strong competition with the rest of the community. Although there are many ways to be uneven (i.e., different species could dominate to different extents), high evenness requires all species to occur at similar abundances, and this provides more consistent outcomes for persistence and productivity, which can be visualized as the declining variance in survival probability and relative biomass with increasing evenness in figure 1.

Some empirical support exists for our finding that the evenness-productivity relationship should be more positive when the dominant species has a high niche overlap with (i.e., a high competitive effect on) the rest of the community. Nyfeler et al. (2009) found that the evenness-productivity relationship was consistently positive, but its slope declined with added nitrogen (i.e., reduced resource competition). Similarly, studies that compared experimental treatments of tall plants only (high niche overlap) with a mixture of tall and short plants (lower niche overlap) have found more positive evenness-productivity relationships in the high niche overlap treatment (i.e., all plants tall; Isbell et al. 2008; Huang et al. 2013). This may partly explain previous inconsistencies in the relationship between evenness and productivity found in empirical studies (table A2).

The insurance hypothesis (Yachi and Loreau 1999) posits that high species richness buffers community responses to perturbation. Superficially, this may suggest that production can be maximized by adding to a single dominant a number of species at low abundance that act as a buffer. In contrast, our results demonstrate that for a given level of species richness, any system dominated by a single or a few species (low evenness) is operating at the brink of extinction of one or more species, such that this buffer will erode over time. Thus, conservation of biodiversity within production systems would appear, from our results, to be least effective when the system is dominated by a single highly productive species, and diverse plantings may therefore benefit associated self-colonizing biodiversity as well as production (Erskine et al. 2006).

High species evenness has long been known to characterize natural communities (Odum 1969), and this has led to its widespread use as a measure of disturbance. We have demonstrated that declining evenness is also a general indicator of further species extinctions, and this result is highly reproducible across different niche-competition communities. As plants are basal species in many food webs, our results raise a number of interesting questions about the extent to which unevenness in plants may indicate decreasing tolerance to perturbations at higher trophic levels and how declining evenness with increasing perturbation may affect food-web structure by altering frequencies of species encounter. An interesting hypothesis would be that disturbance generates low species evenness at multiple trophic levels and that this would lead to more frequent interactions involving dominant species and the loss of interactions among rare species. Such a hypothesis would be congruent with observed and simulated changes to species interaction networks under global change drivers, such as invasion (Aizen et al. 2008), land-use intensification (Tylianakis et al. 2007), changes in interaction strengths (Tylianakis et al. 2008; Saavedra et al. 2013), and climate warming and nitrogen deposition (de Sassi et al. 2012), and it requires further exploration. Furthermore, we have assumed that species evenness is only a function of changes in demographic characteristics. Future work should also explore the extent to which species turnover, migration, changes in interspecific interactions, and long-term dynamics, among other factors, affect the relationship of species evenness with species survival probability and biomass production. However, these new potential studies should not forget that, without disentangling the competitive effects in these communities, analyses can lead to misleading results.

\section{Acknowledgments}

Funding was provided by the European Research Council through an Advanced Grant (J.B.), the Marsden Fund of New Zealand (UOC0802; G.P., J.M.T.), the Natural Sciences and Engineering Research Council of Canada, Education New Zealand, the University of Canterbury (C.M.F.), a Rutherford Discovery Fellowship (J.M.T.), and the Swiss National Science Foundation (31003A_138489; L.-F.B.). D. Stouffer and the Tylianakis/Stouffer laboratory group provided helpful comments on an early draft. A preliminary version of the manuscript was written while S.S. was present at Estación Biológica de Doñana (EBD-CSIC). The authors declare no competing financial interests. All authors contributed to the design of the study; R.P.R. and S.S. performed modeling work and analyzed output data; G.P., C.M.F., and J.M.T. compiled tables A1 and A2; R.P.R., S.S., and J.M.T. wrote the first draft of the manuscript; and all authors contributed substantially to revisions.

\section{Literature Cited}

Aizen, M. A., C. L. Morales, and J. M. Morales. 2008. Invasive mutualists erode native pollination webs. PloS Biology 6:e31

Bastolla, U., M. Lässig, S. C. Manrubia, and A Valleriani. 2005. Biodiversity in model ecosystems, I: coexistence conditions for competing species. Journal of Theoretical Biology 235:521-530.

Cardinale, B. J., D. S. Srivastava, J. Emmett Duffy, J. P. Wright, A. L. Downing, M. Sankaran, and C. Jouseau. 2006. Effects of biodiver- 
sity on the functioning of trophic groups and ecosystems. Nature 443:989-992.

Case, T. J. 1990. Invasion resistance arises in strongly interacting species-rich model competition communities. Proceedings of the National Academy of Sciences of the USA 87:9610-9614.

Chapin, F. S., E. S. Zavaleta, V. T. Eviner, R. L. Naylor, P. M. Vitousek, H. L. Reynolds, D. U. Hooper, et al. 2000. Consequences of changing biodiversity. Nature 405:234-242.

de Sassi, C., P. P. A. Staniczenko, and J. M. Tylianakis. 2012. Warming and nitrogen affect size structuring and density dependence in a host-parasitoid food web. Philosophical Transactions of the Royal Society B: Biological Sciences 367:3033-3041.

Erskine, P. D., D. Lamb, and M. Bristow. 2006. Tree species diversity and ecosystem function: can tropical multi-species plantations generate greater productivity? Forest Ecology and Management 233:205-210.

Halloy, S. R. P., and B. I. P. Barratt. 2007. Patterns of abundance and morphology as indicators of ecosystem status: a meta-analysis. Ecological Complexity 4:128-147.

Hector, A., and R. Bagchi. 2007. Biodiversity and ecosystem multifunctionality. Nature 488:188-190.

Hillebrand, H., D. M. Bennett, and M. W. Cadotte. 2008. Consequences of dominance: a review of evenness effects on local and regional ecosystem processes. Ecology 89:1510-1520.

Hillebrand, H., and V. Lehmpfuhl. 2011. Resource stoichiometry and consumers control the biodiversity-productivity relationship in pelagic metacommunities. American Naturalist 178:171-181.

Hooper, D. U., F. S. Chapin, J. J. Ewel, A. Hector, P. Inchausti, S. Lavorel, J. H. Lawton, et al. 2005. Effects of biodiversity on ecosystem functioning: a consenus of current knowledge. Ecological Monographs 75:3-35.

Huang, Y., L. Martin, F. Isbell, and B. Wilsey. 2013. Is community persistence related to diversity? a test with prairie species in a longterm experiment. Basic and Applied Ecology 14:199-207.

Huston, M. 1979. A general hypothesis of species diversity. American Naturalist 113:81-101.

Isbell, F. I., D. A. Losure, K. A. Yurkonis, and B. J. Wilsey. 2008. Diversity-productivity relationships in two ecologically realistic rarity-extinction scenarios. Oikos 117:996-1005.

Laliberté, E., H. Lambers, D. A. Norton, J. M. Tylianakis, and M. A. Hustonand. 2013. A long-term experimental test of the dynamic equilibrium model of species diversity. Oecologia 171:439-448.

Levins, R. 1968. Evolution in changing environments: some theoretical explorations. Princeton University Press, Princeton, NJ.

Logofet, D. O. 1993. Matrices and graphs: stability problems in mathematical ecology. CRC Press, Boca Raton, FL.

Loreau, M. 1998. Separating sampling and other effects in biodiversity experiments. Oikos 82:600-602.

- 2010. From population to ecosystems: theoretical foundations for a new ecological synthesis. Princeton University Press, Princeton, NJ.

MacArthur, R., and R. Levins. 1967. The limiting similarity, convergence, and divergence of coexisting species. American Naturalist 101:377-385.

Margalef, R. 1963. On certain unifying principles in ecology. American Naturalist 97:357-374.

1968. Perspectives in ecological theory. University of Chicago Press, Chicago.

Mattingly, B. W., R. Hewlate, and H. L. Reynolds. 2007. Species evenness and invasion resistance of experimental grassland communities. Oikos 116:1164-1170.
Mulder, C. P. H., E. Bazeley-White, P. G. Dimitrakopoulos, A. Hector, M. Scherer-Lorenzen, and B. Schmid. 2004. Species evenness and productivity in experimental plant communities. Oikos 107: $50-63$.

Nijs, I., and J. Roy. 2000. How important are species richness, species evenness and interspecific differences to productivity? a mathematical model. Oikos 88:57-66.

Norberg, J., D. P. Swaney, J. Dushoff, J. Lin, R. Casagrandi, and S. A. Levin. 2001. Phenotypic diversity and ecosystem functioning in changing environments: a theoretical framework. Proceedings of the National Academy of Sciences of the USA 98:11376-11381.

Nyfeler, D., O. Huguenin-Elie, M. Suter, E. Frossard, J. Connolly, and A. Lüscher. 2009. Strong mixture effects among four species in fertilized agricultural grassland led to persistent and consistent transgressive overyielding. Journal of Applied Ecology 46:683-691.

Odum, E. P. 1969. The strategy of ecosystem development. Science 164:262-270.

Preston, F. W. 1948. The commonness, and rarity, of species. Ecology 29:254-283.

Rohr, R. P., S. Saavedra, and J. Bascompte. 2014. On the structural stability of mutualistic systems. Science 345:1253497.

Rohr, R. P., S. Saavedra, G. Peralta, C. M. Frost, L.-F. Bersier, J. Bascompte, and J. M. Tylianakis. 2016. Data from: Persist or produce: a community trade-off tuned by species evenness. American Naturalist, Dryad Digital Repository, http://dx.doi.org/10.5061/dryad .sp45r.

Saavedra, S., R. P. Rohr, V. Dakos, and J. Bascompte. 2013. Estimating the tolerance of species to the effects of global environmental change. Nature Communication 4:2350.

Saavedra, S., R. P. Rohr, M. A. Fortuna, N. Selva, and J. Bascompte. 2016a. Seasonal species interactions minimize the impact of species turnover on the likelihood of community persistence. Ecology 97:865-873.

Saavedra, S., R. P. Rohr, L. J. Gilarranz, and J. Bascompte. 2014. How structurally stable are global socioeconomic systems? Journal of the Royal Society Interface 11:20140693.

Saavedra, S., R. P. Rohr, J. M. Olesen, and J. Bascompte. $2016 b$. Nested species interactions promote feasibility over stability during the assembly of a pollinator community. Ecology and Evolution 6:997-1007. doi:10.1002/ece3.1930.

Stirling, G., and B. Wilsey. 2001. Empirical relationships between species richness, evenness, and proportional diversity. American Naturalist 158:286-299.

Sugihara, G., L.-F. Bersier, R. E. Southwood, S. L. Pimm, and R. M. May. 2003. Predicted correspondence between species abundances and dendrograms of niche similarities. Proceedings of the National Academy of Sciences of the USA 100:5246-5251.

Svirezhev, Y. M., and D. O. Logofet. 1983. Stability of biological communities. Mir, Moscow.

Tilman, D., D. Wedin, and J. Knops. 1996. Productivity and sustainability influenced by biodiversity in grassland ecosystems. Nature 379:718-720.

Tokeshi, M. 1990. Niche apportionment or random assortment: species abundance patterns revisited. Journal of Animal Ecology 59: $1129-1146$.

Tylianakis, J. M., R. K. Didham, J. Bascompte, and D. A. Wardle. 2008. Global change and species interactions in terrestrial ecosystems. Ecology Letters 11:1351-1363.

Tylianakis, J. M., T. Tscharntke, and O. T. Lewis. 2007. Habitat modification alters the structure of tropical host. Nature 445:202-205. 
Vandermeer, J. H. 1970. The community matrix and the number of species in a community. American Naturalist 104:78-83.

Vellend, M., L. Baeten, I. H. Myers-Smith, S. C. Elmendorf, R. Beauséjour, C. D. Brown, P. De Frenne, K. Verheyen, and S. Wipf. 2013. Global meta-analysis reveals no net change in local-scale plant biodiversity over time. Proceedings of the National Academy of Sciences of the USA 110:19456-19459.

Volterra, V. 1931. Leçons sur la théorie mathématique de la lutte pour la vie. Gauthier-Villars, Paris.

Wardle, D. A., O. Zachrisson, G. Hörnberg, and C. Gallet. 1997. The influence of island area on ecosystem properties. Science 227:12961299.

Wilsey, B. J., and C. Potvin. 2000. Biodiversity and ecosystem functioning: importance of species evenness in an old field. Ecology 81:887-892.

Wittebolle, L., M. Marzorati, L. Clement, A. Balloi, D. Daffonchio, K. Heylen, P. De-Vos, W. Verstraete, and N. Boon. 2009. Initial community evenness favours functionality under selective stress. Nature 458:623-626.

Yachi, S., and M. Loreau. 1999. Biodiversity and ecosystem productivity in a fluctuating environment: the insurance hypothesis. Proceedings of the National Academy of Sciences of the USA 96:14631468.

\section{References Cited Only in the Online Appendixes}

Assaf, T., W. Beyschlag, and J. Isselstein. 2011. The relationship between plant diversity and productivity in natural and in managed grassland. Applied Ecology and Environmental Research 9:157166.

Brassard, B. W., H. Y. H. Chen, X. Cavard, J. Laganière, P. B. Reich, Y. Bergeron, D. Paré, and Z. Yuan. 2013. Tree species diversity increases fine root productivity through increased soil volume filling. Journal of Ecology 101:210-219.

Chalcraft, D. R., B. J. Wilsey, C. Bowles, and M. R. Willig. 2009. The relationship between productivity and multiple aspects of biodiversity in six grassland communities. Biodiversity and Conservation 18:91-104

Collet, C., F. Ningre, I. Barbeito, A. Arnaud, and A. Piboule. 2014. Response of tree growth and species coexistence to density and species evenness in a young forest plantation with two competing species. Annals of Botany 113:711-719.

Gamfeldt, L., and H. Hillebrand. 2011. Effects of total resources, resource ratios, and species richness on algal productivity and evenness at both metacommunity and local scales. PLoS ONE 6:e21972.

Kirwan, L., A. Lüscher, M. T. Sebastià, J. A. Finn, R. P. Collins, C. Porqueddu, A. Helgadottir, et al. 2007. Evenness drives consistent diversity effects in intensive grassland systems across 28 European sites. Journal of Ecology 95:530-539.

Larpkern, P., Ø. Totland, and S. R. Moe. 2011. Do disturbance and productivity influence evenness of seedling, sapling and adult tree species across a semi-deciduous tropical forest landscape? Oikos 120:623-629.

Lemieux, J., and M. Cusson. 2014. Effects of habitat-forming species richness, evenness, identity, and abundance on benthic intertidal community establishment and productivity. PLoS ONE 9:e109261.

Mischkolz, J. M., M. P. Schellenberg, and E. G. Lamb. 2016. Assembling productive communities of native grass and legume species: finding the right mix. Applied Vegetation Science 19:111-121.

Mouillot, D., M. George-Nascimento, and R. Poulin. 2005. Richness, structure and functioning in metazoan parasite communities. Oikos 109:447-460.

Napoléon, C., L. Fiant, V. Raimbault, P. Riou, and P. Claquin. 2014. Dynamics of phytoplankton diversity structure and primary productivity in the English Channel. Marine Ecology Progress Series 505:49-64.

Piñeiro-Guerra, J. M., C. Fagúndez-Pachón, M. Oesterheld, and M. Arim. 2014. Biodiversity-productivity relationship in ponds: community and metacommunity patterns along time and environmental gradients. Austral Ecology 39:808-818.

Polley, H. W., B. J. Wilsey, and J. D. Derner. 2003. Do species evenness and plant density influence the magnitude of selection and complementarity effects in annual plant species mixtures? Ecology Letters 6:248-256.

Ribas, A., R. Llurba, F. Gouriveau, N. Altimir, J. Connolly, and M. T. Sebastià. 2015. Plant identity and evenness affect yield and trace gas exchanges in forage mixtures. Plant and Soil 391:93-108.

Sagar, R., and J. Singh. 2006. Tree density, basal area and species diversity in a disturbed dry tropical forest of northern India: implications for conservation. Environmental Conservation 33:256.

Schmitz, M., D. F. B. Flynn, P. N. Mwangi, R. Schmid, M. SchererLorenzen, W. W. Weisser, and B. Schmid. 2013. Consistent effects of biodiversity on ecosystem functioning under varying density and evenness. Folia Geobotanica 48:335-353.

Stevens, M. H. H., and W. P. Carson. 2001. Phenological complementarity, species diversity, and ecosystem function. Oikos 92: 291-296.

Tracy, B. F., and M. A. Sanderson. 2004. Forage productivity, species evenness and weed invasion in pasture communities. Agriculture, Ecosystems, and Environment 102:175-183.

Wills, C., K. E. Harms, R. Condit, D. King, J. Thompson, F. He, H. C. Muller-Landau, et al. 2006. Nonrandom processes maintain diversity in tropical forests. Science 311:527-531.

Wilsey, B. J., and H. W. Polley. 2004. Realistically low species evenness does not alter grassland species-richness-productivity relationships. Ecology 85:2693-2700.

Zhang, Y., H. Y. H. Chen, and P. B. Reich. 2012. Forest productivity increases with evenness, species richness and trait variation: a global meta-analysis. Journal of Ecology 100:742-749.

Associate Editor: Mathew A. Leibold Editor: Yannis Michalakis 


\section{Appendix A from R. P. Rohr et al., "Persist or Produce: A Community Trade-Off Tuned by Species Evenness" \\ (Am. Nat., vol. 188, no. 4, p. 000)}

Compiled Empirical Studies

Table A1: Overview of results from studies that have examined the relationship between species evenness and species persistence

\begin{tabular}{|c|c|c|c|c|}
\hline Study & Response variable & $\begin{array}{l}\text { Relationship with } \\
\text { species evenness }\end{array}$ & Study system & Details \\
\hline $\begin{array}{l}\text { Wilsey and Polley } \\
2004\end{array}$ & Persistence & $\begin{array}{l}\text { Positive (extinction rates in } \\
\text { second year higher with low } \\
\text { evenness, as rare species } \\
\text { with low growth rates } \\
\text { became extinct) }\end{array}$ & $\begin{array}{c}\text { Grassland plant } \\
\text { communities }\end{array}$ & $\begin{array}{l}\text { Experiment manipulating rank } \\
\text { abundance slopes at fixed rich- } \\
\text { ness and biomass; same species in } \\
\text { high and low evenness treatments; } \\
\text { mix of } \mathrm{C}_{3} \text { and } \mathrm{C}_{4} \text { grasses and } \\
\text { forbs }\end{array}$ \\
\hline Wills et al. 2006 & Persistence & $\begin{array}{l}\text { Positive (rare species have } \\
\text { higher survival rate than } \\
\text { common species, which in } \\
\text { turn promotes diversity } \\
\text { maintenance) }\end{array}$ & $\begin{array}{l}\text { Forest plant } \\
\text { communities }\end{array}$ & $\begin{array}{l}\text { Census data from seven tropical } \\
\text { forest dynamics plots }\end{array}$ \\
\hline Isbell et al. 2008 & Persistence & $\begin{array}{l}\text { Positive (although species } \\
\text { richness declined only in } \\
\text { lowest evenness treatment) }\end{array}$ & $\begin{array}{l}\text { Tallgrass prairie plants in } \\
\text { an abandoned pasture } \\
\text { (six species) }\end{array}$ & $\begin{array}{l}\text { Experimental plots with initial } \\
\text { evenness and richness manipu- } \\
\text { lated; plant height (tall vs. dis- } \\
\text { similar) also manipulated }\end{array}$ \\
\hline Huang et al. 2013 & Persistence & $\begin{array}{l}\text { Positive in tall plots (high } \\
\text { niche overlap) but not in } \\
\text { dissimilar-height plots }\end{array}$ & Grassland plants & $\begin{array}{l}\text { Field experiment manipulating plant } \\
\text { diversity and height classes }\end{array}$ \\
\hline Collet et al. 2014 & $\begin{array}{l}\text { Persistence (coexistence } \\
\text { of both tree species) }\end{array}$ & No relationship & $\begin{array}{l}\text { Two tree species (Fagus } \\
\text { sylvatica and Acer } \\
\text { pseudoplatanus) }\end{array}$ & $\begin{array}{l}\text { Twelve-year-old experimental tree } \\
\text { plantation }\end{array}$ \\
\hline
\end{tabular}

Note: In summary, four of five studies found a positive relationship between species evenness and species persistence, while one study found no relationship.

Table A2: Overview of results from studies that have examined the relationship between species evenness and productivity

\begin{tabular}{|c|c|c|c|c|}
\hline Study & Response variable & $\begin{array}{l}\text { Relationship with } \\
\text { species evenness }\end{array}$ & Study system & Details \\
\hline $\begin{array}{l}\text { Tracy and Sanderson } \\
2004\end{array}$ & Percent forage cover & Positive & Pasture plants & $\begin{array}{l}\text { Survey of pasture plants (identity } \\
\text { not provided) }\end{array}$ \\
\hline Schmitz et al. 2013 & Aboveground biomass & $\begin{array}{l}\text { Positive effect of planted } \\
\text { evenness declined over time } \\
\text { as realized evenness de- } \\
\text { clined; consistent positive } \\
\text { effect of realized evenness }\end{array}$ & Grassland plants & $\begin{array}{l}\text { Experiment manipulating even- } \\
\text { ness at fixed richness; species } \\
\text { were made dominant at ran- } \\
\text { dom by planting density }\end{array}$ \\
\hline Nyfeler et al. 2009 & Aboveground biomass & Positive & Grassland plants & $\begin{array}{l}\text { Experiment manipulating even- } \\
\text { ness at fixed richness; species } \\
\text { were made dominant at ran- } \\
\text { dom by planting density; ef- } \\
\text { fect greatest when proportions } \\
\text { of grasses and legumes are } \\
\text { even but also significant } \\
\text { within grasses or legumes }\end{array}$ \\
\hline Kirwan et al. 2007 & $\begin{array}{l}\text { Total aboveground } \\
\text { biomass }\end{array}$ & Positive in 25 of 28 sites & Grassland plants & $\begin{array}{l}\text { Experimental manipulation of } \\
\text { four species at } 28 \text { European } \\
\text { sites }\end{array}$ \\
\hline
\end{tabular}


Table A2 (Continued)

\begin{tabular}{|c|c|c|c|c|}
\hline Study & Response variable & $\begin{array}{l}\text { Relationship with } \\
\text { species evenness }\end{array}$ & Study system & Details \\
\hline Ribas et al. 2015 & Aboveground biomass & Positive & $\begin{array}{l}\text { Forage plant communi- } \\
\text { ties }\end{array}$ & $\begin{array}{l}\text { Field experiment using three } \\
\text { species at three treatments: } \\
\text { monocultures, even mix, or } \\
\text { uneven (one species at } 80 \% \text { ) } \\
\text { mixtures }\end{array}$ \\
\hline $\begin{array}{l}\text { Hillebrand and } \\
\text { Lehmpfuhl } 2011\end{array}$ & $\begin{array}{l}\text { Resource use efficiency } \\
\text { (RUE, biomass per } \\
\text { unit P) }\end{array}$ & $\begin{array}{l}\text { Positive (in absence of } \\
\text { consumers) but depended } \\
\text { on } \mathrm{N}: \mathrm{P} \text { ratio }\end{array}$ & Phytoplankton & $\begin{array}{l}\text { Experimental metacommunity, } \\
\text { where evenness and richness } \\
\text { were altered by varying } \mathrm{N} \text { and } \\
\mathrm{P} \text { supply }\end{array}$ \\
\hline Collet et al. 2014 & $\begin{array}{l}\text { Stand productivity } \\
\text { (measured as tree } \\
\text { height and stem } \\
\text { diameter) }\end{array}$ & Positive & $\begin{array}{l}\text { Two tree species (Fagus } \\
\text { sylvatica and Acer } \\
\text { pseudoplatanus) }\end{array}$ & $\begin{array}{l}\text { Twelve-year-old experimental } \\
\text { tree plantation }\end{array}$ \\
\hline Zhang et al. 2012 & $\begin{array}{l}\text { Aboveground produc- } \\
\text { tivity }\end{array}$ & Positive & Forests & $\begin{array}{l}\text { Meta-analysis of } 54 \text { diversity- } \\
\text { productivity studies in forest } \\
\text { systems, both planted and } \\
\text { natural }\end{array}$ \\
\hline $\begin{array}{l}\text { Stevens and Carson } \\
2001\end{array}$ & Total annual cover & Positive & $\begin{array}{l}\text { Successional plant } \\
\text { community }\end{array}$ & $\begin{array}{l}\text { Observational study of form- } \\
\text { dominated community } 15 \\
\text { years after abandonment of } \\
\text { agriculture }\end{array}$ \\
\hline Mattingly et al. 2007 & $\begin{array}{l}\text { Above- and below- } \\
\text { ground biomass } \\
\text { production }\end{array}$ & Positive & Plant communities & $\begin{array}{l}\text { Greenhouse experiment manipu- } \\
\text { lating evenness of US native } \\
\text { prairie grassland species }\end{array}$ \\
\hline Sagar and Singh 2006 & Tree basal area & Positive & Tree communities & $\begin{array}{l}\text { Observational study of tropical } \\
\text { dry forests }\end{array}$ \\
\hline $\begin{array}{l}\text { Wilsey and Potvin } \\
2000\end{array}$ & $\begin{array}{l}\text { Total, above-, and be- } \\
\text { lowground biomass }\end{array}$ & $\begin{array}{l}\text { Positive for total and below- } \\
\text { ground; aboveground varied } \\
\text { with identity of dominant } \\
\text { species }\end{array}$ & Old field plants & $\begin{array}{l}\text { Experimental manipulation of } \\
\text { evenness and identity of dom- } \\
\text { inant plant; species composi- } \\
\text { tion (three species) held con- } \\
\text { stant }\end{array}$ \\
\hline $\begin{array}{l}\text { Wilsey and Potvin } \\
2004\end{array}$ & $\begin{array}{l}\text { Peak aboveground bio- } \\
\text { mass and root biomass }\end{array}$ & $\begin{array}{l}\text { None for peak aboveground } \\
\text { biomass, positive for shal- } \\
\text { low root biomass, positive } \\
\text { richness } \times \text { evenness inter- } \\
\text { action for deep roots }\end{array}$ & Grassland plants & $\begin{array}{l}\text { Experiment manipulating rank } \\
\text { abundance slopes at fixed } \\
\text { richness and biomass; same } \\
\text { species in high and low even- } \\
\text { ness treatments; mix of } \mathrm{C}_{3} \text { and } \\
\mathrm{C}_{4} \text { grasses and forbs }\end{array}$ \\
\hline Brassard et al. 2013 & $\begin{array}{l}\text { Fine root biomass } \\
\text { of trees }\end{array}$ & $\begin{array}{l}\text { Positive for annual root pro- } \\
\text { duction, but effect was most } \\
\text { apparent during summer } \\
\text { months, with low to no ef- } \\
\text { fect in spring and fall }\end{array}$ & Boreal forest & $\begin{array}{l}\text { Natural stands dominated by } \\
\text { coniferous or broadleaved } \\
\text { species }\end{array}$ \\
\hline Assaf et al. 2011 & Aboveground biomass & $\begin{array}{l}\text { Positive in managed } \\
\text { grasslands, no relationship } \\
\text { in natural grasslands }\end{array}$ & Grassland plants & $\begin{array}{l}\text { Field observations of agricultur- } \\
\text { ally managed and natural } \\
\text { grasslands }\end{array}$ \\
\hline Huang et al. 2013 & $\begin{array}{l}\text { Peak aboveground } \\
\text { biomass }\end{array}$ & $\begin{array}{l}\text { Positive in plots planted only } \\
\text { with tall plant species, no } \\
\text { relationship in plots with tall } \\
\text { and short plant species } \\
\text { combined }\end{array}$ & Grassland plants & $\begin{array}{l}\text { Field experiment manipulating } \\
\text { plant diversity and height } \\
\text { classes }\end{array}$ \\
\hline Polley et al. 2003 & $\begin{array}{l}\text { Net biodiversity effect } \\
\text { (productivity of } \\
\text { mixtures relative to }\end{array}$ & $\begin{array}{l}\text { Positive effect in only two of } \\
\text { six species pairs }\end{array}$ & Grassland plants & $\begin{array}{l}\text { Field experiment with two grass } \\
\text { and two forb species }\end{array}$ \\
\hline
\end{tabular}

mixtures relative to monocultures) 
Table A2 (Continued)

\begin{tabular}{|c|c|c|c|c|}
\hline Study & Response variable & $\begin{array}{l}\text { Relationship with } \\
\text { species evenness }\end{array}$ & Study system & Details \\
\hline Isbell et al. 2008 & Aboveground biomass & $\begin{array}{l}\text { No main effect of evenness, but } \\
\text { interaction with plant height; } \\
\text { marginally significant posi- } \\
\text { tive relationship when there } \\
\text { was a dissimilarity in height }\end{array}$ & Tallgrass prairie & $\begin{array}{l}\text { Experimental plots with initial } \\
\text { evenness and richness manip- } \\
\text { ulated; plant height (tall vs. } \\
\text { dissimilar) also manipulated }\end{array}$ \\
\hline Mischkolz et al. 2016 & Aboveground biomass & No effect & $\begin{array}{l}\text { Macrophytes in ephem- } \\
\text { eral ponds }\end{array}$ & $\begin{array}{l}\text { Observational study of natural } \\
\text { ephemeral ponds }\end{array}$ \\
\hline Chalcraft et al. 2009 & Aboveground biomass & $\begin{array}{l}\text { Positive, negative, and no ef- } \\
\text { fect; response varied across } \\
\text { the six sites and between } \\
\text { years }\end{array}$ & Grassland plants & $\begin{array}{l}\text { Observational study of six sites } \\
\text { along productivity gradient }\end{array}$ \\
\hline $\begin{array}{l}\text { Gamfeldt and } \\
\text { Hillebrand } 2011\end{array}$ & $\begin{array}{l}\text { Resource use efficiency } \\
\text { (RUE, biovolume per } \\
\text { unit P) }\end{array}$ & No effect & Algae & $\begin{array}{l}\text { Experimental aquatic } \\
\text { metacommunities }\end{array}$ \\
\hline Piñeiro-Guerra 2014 & Biomass & No effect overall & $\begin{array}{l}\text { Macrophytes in ephem- } \\
\text { eral ponds }\end{array}$ & $\begin{array}{l}\text { Observational study of natural } \\
\text { ephemeral ponds }\end{array}$ \\
\hline $\begin{array}{l}\text { Lemieux and Cusson } \\
\qquad 2014\end{array}$ & $\begin{array}{l}\text { Net and gross primary } \\
\text { productivity, commu- } \\
\text { nity respiration }\end{array}$ & No effect on any measure & $\begin{array}{l}\text { Benthic intertidal habitat- } \\
\text { forming species } \\
\text { (macroalgae and } \\
\text { mussels) }\end{array}$ & $\begin{array}{l}\text { Field experiment in intertidal } \\
\text { zone of estuary }\end{array}$ \\
\hline Larpkern et al. 2011 & $\begin{array}{l}\text { Aboveground biomass } \\
\text { (plant height and di- } \\
\text { ameter) }\end{array}$ & $\begin{array}{l}\text { Negative for adult woody spe- } \\
\text { cies, no relationship with } \\
\text { saplings }\end{array}$ & $\begin{array}{l}\text { Bamboo deciduous and } \\
\text { mixed deciduous for- } \\
\text { est }\end{array}$ & $\begin{array}{l}\text { Observational study that focused } \\
\text { on effect of productivity on } \\
\text { evenness }\end{array}$ \\
\hline Mouillot et al. 2005 & $\begin{array}{l}\text { Volumetric abundance } \\
\text { (volume of all parasite } \\
\text { species per individual } \\
\text { host) }\end{array}$ & $\begin{array}{l}\text { Negative (logarithmically de- } \\
\text { creasing) }\end{array}$ & $\begin{array}{l}\text { Metazoan parasite com- } \\
\text { munities on } 15 \text { species } \\
\text { of marine fish }\end{array}$ & $\begin{array}{l}\text { Adult fish sampled from coastal } \\
\text { Chile, dissected for parasites }\end{array}$ \\
\hline Napoleon et al. 2014 & $\begin{array}{l}\text { Maximum primary pro- } \\
\text { duction and maximum } \\
\text { productivity }\end{array}$ & $\begin{array}{l}\text { Negative (parabolic) relation- } \\
\text { ship for primary production, } \\
\text { no relationship with produc- } \\
\text { tivity }\end{array}$ & $\begin{array}{l}\text { Natural marine phyto- } \\
\text { plankton communities }\end{array}$ & $\begin{array}{l}\text { Natural marine phytoplankton } \\
\text { communities }\end{array}$ \\
\hline
\end{tabular}

Note: In summary, 12 of 26 studies found a positive relationship between biomass production and evenness; eight studies found mixed outcomes, three found no relationship, and three found a negative effect. 


\section{Appendix B from R. P. Rohr et al., "Persist or Produce: A Community Trade-Off Tuned by Species Evenness" \\ (Am. Nat., vol. 188, no. 4, p. 000)}

\section{Generalized Niche Overlap Matrix}

Here we generalize equation (2), which computes the niche overlap between two species. Generally, we can assume that a $D$-dimensional niche of a species is represented by a multivariate Gaussian-like function with a different width in each dimension $\left(\sigma_{1}, \ldots, \sigma_{N}\right)$. This set of niche width values is species dependent, and the amplitude of the niche curve is also species dependent $\left(a_{i}\right)$. Therefore, a generalized niche function is given by the following equation:

$$
f_{i}(\boldsymbol{x})=\frac{a_{N}}{(2 \pi)^{1 / 2} \sigma_{1} \cdots \sigma_{N}} \exp \left(-\frac{\left(x_{1}-\mu_{1}\right)^{2}}{2 \sigma_{1}^{2}}-\cdots-\frac{\left(x_{N}-\mu_{N}\right)^{2}}{2 \sigma_{N}^{2}}\right),
$$

where $\mu_{1}, \ldots, \mu_{N}$ is the position of the species in the $N$-dimensional niche space.

Following this general niche curve function, we can also compute a generalized formula for the niche overlap between two species $i$ and $j$. It is given by

$$
\begin{aligned}
\alpha_{i j} & =\frac{\int f_{i}(\boldsymbol{x}) f_{j}(\boldsymbol{x}) \mathrm{d} \boldsymbol{x}}{\int f_{i}(\boldsymbol{x}) f_{i}(\boldsymbol{x}) \mathrm{d} \boldsymbol{x}} \\
& =\frac{a_{i}}{a_{j}} \frac{2 \sigma_{1}}{\sqrt{\sigma_{1}^{2}+\nu_{1}^{2}}} \cdots \frac{2 \sigma_{N}}{\sqrt{\sigma_{N}^{2}+\nu_{N}^{2}}} \exp \left(-\frac{\left(\mu_{1}-\tau_{1}\right)^{2}}{2\left(\sigma_{1}^{2}+\nu_{1}^{2}\right)}-\cdots-\frac{\left(\mu_{N}-\tau_{N}\right)^{2}}{2\left(\sigma_{N}^{2}+\nu_{N}^{2}\right)}\right),
\end{aligned}
$$

where $\left(\mu_{1}, \ldots, \mu_{N}\right),\left(\sigma_{1}, \ldots, \sigma_{N}\right)$, and $a_{i}$ are the niche position, niche width, and niche amplitude for species $i$, respectively, and $\left(\tau_{1}, \ldots, \tau_{N}\right),\left(v_{1}, \ldots, v_{N}\right)$, and $a_{j}$ are the niche position, niche width, and niche height for species $i$, respectively. Note that this generalized formula allows us to generate asymmetric niche overlap matrices. The qualitative results of the article hold when using niche overlap matrices generated from equation (B2) instead of equation (2) (results not shown). 


\section{Appendix C from R. P. Rohr et al., "Persist or Produce: A Community Trade-Off Tuned by Species Evenness" \\ (Am. Nat., vol. 188, no. 4, p. 000)}

\section{Relative Biomass and Species Dominance}

Here we give the mathematical proof that lower average niche overlap of the dominating species leads to higher relative biomass and vice versa. We start by writing explicitly the system of linear equations linking the vector of carrying capacities $(\boldsymbol{K})$ and the biomasses $\left(\boldsymbol{N}^{*}\right)$ at equilibrium:

$$
\begin{array}{ccccccccc}
K_{1} & = & N_{1}^{*} & + & \alpha_{12} N_{2}^{*} & + & \cdots & + & \alpha_{1 S} N_{S}^{*} \\
K_{2} & = & \alpha_{21} N_{1}^{*} & + & N_{2}^{*} & + & \cdots & + & \alpha_{2 S} N_{S}^{*} \\
\vdots & \vdots & \vdots & & \vdots & & & & \vdots \\
K_{S} & = & \alpha_{S 1} N^{*} & + & \alpha_{S 2} N_{2}^{*} & + & \cdots & + & N_{S}^{*}
\end{array} .
$$

Let us assume, without loss of generality, that species 1 is dominating the community. Mathematically, this is equivalent to studying the limit case where the biomasses of the other species go to 0 , that is, $N_{2}^{*}, N_{3}^{*}, \ldots, N_{S}^{*} \rightarrow 0$. In this limit case, the equations linking the carrying capacity to the biomass are given by

$$
\begin{array}{ccc}
K_{1} & = & N_{1}^{*} \\
K_{2} & = & \alpha_{21} N_{1}^{*} \\
\vdots & \vdots & \vdots \\
K_{S} & = & \alpha_{S 1} N_{1}^{*}
\end{array}
$$

By summing these $S$ equations, we obtain the following equation relating the biomass of the dominating species 1 to the sum of the carrying capacities of all species:

$$
\sum_{i} K_{i}=\left(1+\sum_{j \neq 1} \alpha_{j 1}\right) N_{1}^{*}
$$

From this relation, we can analytically derive the relative biomass production of the community with species 1 dominating:

$$
P(\text { species } 1 \text { dominating })=\frac{\sum_{i} N_{i}^{*}}{\sum_{i} K_{i}}=\frac{1}{1+(S-1) \bar{\alpha}_{1}},
$$

where $\bar{\alpha}_{1}$ is the average niche overlap of species 1 defined by $\bar{\alpha}_{1}=\left(\sum_{j \neq 1} \alpha_{j i}\right) /(S-1)$. This formula can be generalized to any arbitrary species $i$ dominating the community by

$$
P(\text { species } 1 \text { dominating })=\frac{\sum_{i} N_{i}^{*}}{\sum_{i} K_{i}}=\frac{1}{1+(S-1) \bar{\alpha}_{1}},
$$

with $\bar{\alpha}_{i}=\left(\sum_{j \neq i} \alpha_{j i}\right) /(S-1)$. From the last equation we deduce that lower average niche overlap of the dominating species leads to larger relative biomass. In fact, the relative biomasses when one species dominates are ranked according to the average niche overlap of the dominating species but in the reverse order. 